\title{
Development of nutrition education material to impart nutritional awareness among tribal adolescent girls of Ranchi district
}

\author{
SNEHA VERMA, VIRGINIA PAUL, AJIT PAUL AND SARITA SHEIKH
}

Received: 11.10.2013; Revised: 13.09.2014; Accepted: 25.09.2014

See end of the paper for authors' affiliations

\section{SNEHA VERMA}

Department of Foods and

Nutrition, Sam Higginbottom

Institute of Agriculture

Technology and Sciences (D.U.), ALLAHABAD (U.P.) INDIA

Email : sneha.verma303@gmail. com
ABSTRACT : The study was performed as per the following objectives to assess the nutritional awareness related to dietary practices, to develop a film strip for nutrition education of selected tribal adolescent girls and to determine the gain in nutritional knowledge of selected adolescent girls through the developed film strip. For the present study adolescent girls of (13-16 years) were selected and divided into two groups, group A consisting of (13-14 years) age and group B consisting (15-16 years) age from 'Doman Dih' village of 'Rahe' block, 'Ranchi' district, state Jharkhand (N=60). The film strip entitled "LADKIYON MAIN POSHAN" was developed for providing the nutritional information and knowledge to the adolescent girls regarding the importance of iron, vitamin A, iodine and their role in our body. In the present study, the nutritional status of adolescent girls and the impact of communication methods on their knowledge, attitude and practices (KAP) were studied as pre-exposure data and post-exposure data. There was the positive impact of the film strip shown, as all the results showed significant $p \leq 0.5$ which means the nutrition education imparted was fruitfully conducted and knowledge was gained in a better way. About 21.7 per cent of the respondents knew about balanced diet and after imparting nutrition education it raised to 66.7 per cent, 58.3 per cent of the respondents knew about the sources of calcium and after the film strip which was shown, it rose to 86.6 per cent, 66.7 per cent of the respondents knew about the deficiency of anaemia and after providing nutrition education, it rose to 78.3 per cent. 38.3 of the respondents knew about vitamin A but after providing nutrition education, it rose to 56.7 per cent. Knowledge level scores of the respondents was also increased after providing nutrition education, 3.3 per cent of the respondents scored very good and after providing nutrition education, it raised to 51.7 per cent. About 11.7 per cent of the respondents scored good and after providing nutrition education, it rose to 26.6 per cent which showed a positive impact of the adolescent girls towards knowledge.

KEY WORDS: Nutrition education, Adolescent girls, Film strip

— HOW TO CITE THIS PAPER : Verma, Sneha, Paul, Virginia, Paul, Ajit and Sheikh, Sarita (2014). Development of nutrition education material to impart nutritional awareness among tribal adolescent girls of Ranchi district. Asian J. Home Sci., 9 (2) : 388-393. 